Jacquelien J. Hillebrand*, Li Zhou, Marilee A. Marcinkus, Maria Datwyler, Susan H. Gawel, Frans Martens, Gerard J. Davis and Annemieke C. Heijboer

\title{
Instability of corticotropin during long-term storage - myth or reality?
}

https://doi.org/10.1515/cclm-2021-0818

Received July 20, 2021; accepted September 21, 2021;

published online October 13, 2021

\section{Abstract}

Objectives: Corticotropin is notorious for its instability. Whereas several studies have investigated its short-term stability in plasma following venous blood sampling, studies on long-term stability are lacking. Here we investigated the long-term storage stability of corticotropin in ethylenediaminetetraacetic acid containing plasma.

Methods: Specimens from healthy volunteers (neat, spiked) were stored in polypropylene microcentrifuge tubes with socket screw-caps at $-20^{\circ} \mathrm{C}$ and $-70^{\circ} \mathrm{C}$ for up to one and a half years. Corticotropin in plasma was measured using an Abbott research only immunoassay. Separately, specimens from patients were collected during diagnostic routine testing and stored in polystyrene tubes with push-caps at $-20^{\circ} \mathrm{C}$ for up to 6 years. In these samples corticotropin hormone was measured using the Diasorin corticotropin immunoassay.

Results: Storage of specimens at $-20^{\circ} \mathrm{C}$ or $-70{ }^{\circ} \mathrm{C}$ for up to one and a half years showed minimal changes $(<11 \%)$ in corticotropin levels, while storage of patient samples at $-20{ }^{\circ} \mathrm{C}$ for up to 6 years showed a significant $(54 \%)$ reduction in corticotropin levels.

Jacquelien J. Hillebrand and Li Zhou contributed equally to this work.

*Corresponding author: Jacquelien J. Hillebrand, PhD, Department of Clinical Chemistry, Endocrine Laboratory, Amsterdam University Medical Centres, Meibergdreef 91105 AZ Amsterdam, The Netherlands, Phone: +31 2056 63127,

E-mail: j.j.hillebrand@amsterdamumc.nl

Li Zhou, Marilee A. Marcinkus, Maria Datwyler, Susan H. Gawel and Gerard J. Davis, Abbott Diagnostics, Abbott Laboratories, Abbott Park, IL, USA

Frans Martens and Annemieke C. Heijboer, Department of Clinical Chemistry, Endocrine Laboratory, Amsterdam Gastroenterology Endocrinology \& Metabolism, Amsterdam University Medical Centres, University of Amsterdam, Vrije Universiteit Amsterdam, Amsterdam, The Netherlands
Conclusions: Corticotropin levels are stable in plasma when stored at $-20^{\circ} \mathrm{C}$ for one and a half years using the Abbott research only assay, but with longer storage time a significant reduction in corticotropin levels can be expected. Once specimens are stored for future corticotropin measurements, one should consider storage time, storage temperature and assay differences.

Keywords: adrenocorticotropic hormone (ACTH); degradation; hormone; plasma; preanalytical; stability.

\section{Introduction}

Corticotropin (adrenocorticotropic hormone, ACTH) is a 39-residue polypeptide tropic hormone secreted by the anterior pituitary gland following hypothalamic corticotropinreleasing hormone release. ACTH is cleaved from precursor hormone pro-opiomelanocortin, and plays an important role in the hypothalamic-pituitary-adrenal axis by stimulating the production and secretion of cortisol from the adrenal cortex. Cortisol regulates ACTH release via a negative feedback loop. Measurements of plasma ACTH are crucial for differential diagnosis of endocrine disorders including Cushing's syndrome and adrenal insufficiency but can be complicated by both preanalytical and analytical factors.

ACTH is notorious for its instability. To prevent proteolytic degradation, it is generally advised to store collected specimens on ice immediately after venepuncture collection, to process specimens in a cooled centrifuge within $1 \mathrm{~h}$, and to prevent freeze-thaw cycles [1, 2]. Hemolysis of the blood specimen and choice of blood collection tube type may also influence ACTH measurements [3, 4]. Recent reports however question ACTH's instability and the true necessity of these cumbersome preanalytical actions [5-7]. For long-term storage, it is generally advised to store specimens at $-70^{\circ} \mathrm{C}$. This may, however, not always be possible in daily practice (for clinical diagnostics or research) because of limited $-70{ }^{\circ} \mathrm{C}$ freezer space. Not only may the storage temperature be critical, but also the storage time [8]. The longer the storage time, the higher the chance of degradation of unstable analytes [9]. To our knowledge, long-term stability studies on ACTH are 
lacking. Therefore, we designed a study to investigate the preanalytical stability of ACTH by measuring ACTH levels in neat and spiked specimens stored at both $-20{ }^{\circ} \mathrm{C}$ and $-70^{\circ} \mathrm{C}$ for one and a half years, and also examined stability of ACTH in neat specimens stored at $-20^{\circ} \mathrm{C}$ for up to 4 and 6 years.

\section{Materials and methods}

\section{Experiments}

In this article we describe two experiments. The first experiment on long-term stability was designed to investigate stability at $-20{ }^{\circ} \mathrm{C}$ and $-70{ }^{\circ} \mathrm{C}$ up until one and a half years in native specimens and spiked plasma specimens. The spiking condition was added to be able to investigate the stability of ACTH at higher concentration levels since it is difficult to obtain neat specimens of sufficient volumes to address this type of long-term stability study. The second experiment was designed to investigate the stability at $-20^{\circ} \mathrm{C}$ in native plasma specimens over a longer period, 4 and 6 years.

\section{Specimens}

Experiment 1: Plasma specimens were obtained from 20 healthy American subjects. All blood specimens from venous sampling were collected on ice in $10 \mathrm{~mL}$ Vacutainer ${ }^{\circledR} \mathrm{K}_{2}$-EDTA blood collection tubes (Becton Dickinson, Franklin Lakes NJ, cat \#BD-366643), centrifuged at $3,000 \times g$ for $10 \mathrm{~min}$ within $5-15 \mathrm{~min}$ and refrigerated. Specimens were, neat or spiked with ACTH (22-1,866 pg/mL ACTH, Bachem, Torrance CA, cat \#4141612), aliquoted $(900 \mu \mathrm{L})$ into $2 \mathrm{~mL}$ polypropylene microcentrifuge tubes with socket screw-caps (VWR Radnor PA, cat \#89004-302) and within $2 \mathrm{~h}$ blood collection stored at both $-20{ }^{\circ} \mathrm{C}$ and $-70^{\circ} \mathrm{C}$. Healthy subjects were recruited from Abbott Laboratories (IL) and signed informed consent forms prior to blood collection of specimens (in accordance with the World Medical Association Declaration of Helsinki). Experiment 2: Plasma specimens were obtained from Dutch patients visiting the Amsterdam University Medical Centers (UMC), the Netherlands between 2012 and 2013 for various indications. Blood specimens from venous sampling were collected on ice in $10 \mathrm{~mL}$ Vacutainer ${ }^{\circledR} \mathrm{K}_{2}$-EDTA blood collection tubes (Becton Dickinson, Franklin Lakes NJ, cat \#BD-366643), centrifuged within $1 \mathrm{~h}$, aliquoted $(1 \mathrm{~mL})$ into $5 \mathrm{~mL}$ polystyrene secondary tubes with violet push-caps (Sarstedt, Nümbrecht, Germany, cat\# 55.475.005, 65.806.511) and within $30 \mathrm{~min}$ stored at $-20^{\circ} \mathrm{C}$ for routine measurement within 10 days ( $T=0 \mathrm{y}$ ) as well as for long-term storage (for potential add-ons) for approximately $4(T=4 \mathrm{y}, \mathrm{n}=20)$ and $6(T=6 \mathrm{y}$, $\mathrm{n}=39$ ) years. Patients consented with the use of the left-over blood specimens for research purposes (in accordance with the World Medical Association Declaration of Helsinki).

\section{Measurements}

Experiment 1: Individual specimens were assayed on the day of processing (month 0 ) and five times (at 1, 3, 9, 12, and 18 months) following storage at both $-20{ }^{\circ} \mathrm{C}$ and $-70{ }^{\circ} \mathrm{C}$ in five replicates each.
Specimens were thawed once on the lab countertop at room temperature, mixed by gentle inversion and centrifuged at 3,000 $\times \mathrm{g}$ for $5 \mathrm{~min}$. Afterwards they were kept at room temperature and quickly analy zed. ACTH results were generated on the ARCHITECT ${ }^{\circledR} i 2000_{\mathrm{SR}}$ automated immunoassay instrument system (Abbott Laboratories, Abbott Park, IL) using a Research Use Only prototype ACTH immunoassay. This two-step dual monoclonal sandwich immunoassay captures $\mathrm{ACTH}_{(1-39)}$ via paramagnetic microparticles coated with an anti-ACTH monoclonal antibody to form a complex with ACTH in the specimen. For detection, an acridinium labeled anti-ACTH monoclonal antibody conjugate is added that binds to the ACTH-microparticle complex and chemiluminescence is triggered by addition of an alkaline $\mathrm{pH}$ solution. The release of the light signal is proportional to the level of ACTH in the specimen [10]. All instrument runs were performed using the same calibrator stock. Within-laboratory imprecision (defined as the summation of between-day, between-run and within-run) results were $<6.7 \%$ at $5 \mathrm{pg} / \mathrm{mL},<4.4 \%$ at $30 \mathrm{pg} / \mathrm{mL},<3.3 \%$ at $200 \mathrm{pg} / \mathrm{mL}$ and $<2.7 \%$ at $2,000 \mathrm{pg} / \mathrm{mL}$ ACTH [11]. Experiment 2: ACTH was measured during routine diagnostics at the Endocrine laboratory of the Amsterdam UMC (The Netherlands). Approximately 4 and 6 years later individual sample aliquots (not thawed before) left-over specimens were thawed (on the lab countertop, at room temperature), gently mixed and centrifuged at 3,000 $\times \mathrm{g}$ for $5 \mathrm{~min}$. Afterwards the stored specimens were kept at room temperature and quickly analyzed using the onestep ACTH sandwich immunoassay specific for $\mathrm{ACTH}_{(1-39)}$ on the Liaison analyzer [12]. This chemiluminescence immunoassay (CLIA) uses two monoclonal antibodies of which the capture antibody is coated to magnetic particles and the detection antibody is linked to an isoluminol derivative (Diasorin, Sallugia, Italy; intra assay variation 5-8\%).

\section{Statistical analyses}

Experiment 1: Simple linear regression analysis was performed by analyzing ACTH results vs. specimen storage time for each neat and spiked specimen stored at $-20{ }^{\circ} \mathrm{C}$ and $-70{ }^{\circ} \mathrm{C}$. This resulted in 80 individual regression lines $(20$ donors $\times 2$ (neat and spiked) $\times 2$ storage conditions). Spiked specimens were further grouped into three subgroups based on spike levels and slope values. Analysis of covariance was performed comparing slopes among donors. A separate-interceptcommon-slope (SICS) model was used to estimate the degradation rate of change over storage time for each of the spiked subgroups and for the neat specimens. Using the SICS model, shift and \% shift at 18 months of specimen storage was estimated for various specimen levels of interest. In addition, observed average $\%$ change for specimens (neat or spiked) from month 0 was calculated at each subsequent time point for each storage condition. Statistical analyses were performed using SAS (Statistical Analysis Software 9.4, SAS Institute Inc, Cary, North Carolina, USA). Experiment 2: Non-parametric Wilcoxon paired t-tests were used to compare baseline ACTH levels with ACTH levels after $4(n=20)$ or $6(n=39)$ years of storage at $-20^{\circ} \mathrm{C}$. Statistical analyses were performed using Graphpad Prism 8.3.0.

\section{Results}

Experiment 1: Storing human plasma specimens for up to one and a half years at $-20{ }^{\circ} \mathrm{C}$ or $-70{ }^{\circ} \mathrm{C}$ had limited 
Neat Specimens Stored at $-20^{\circ} \mathrm{C}$

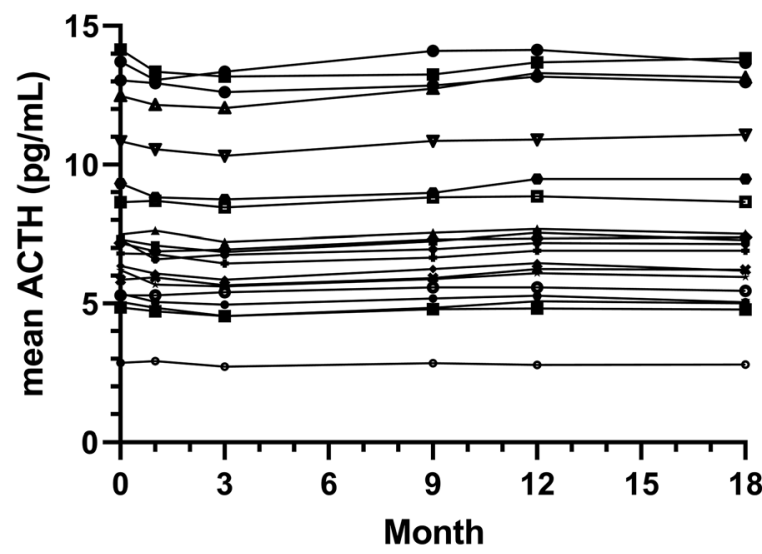

Spiked Specimens Stored at $-20^{\circ} \mathrm{C}$

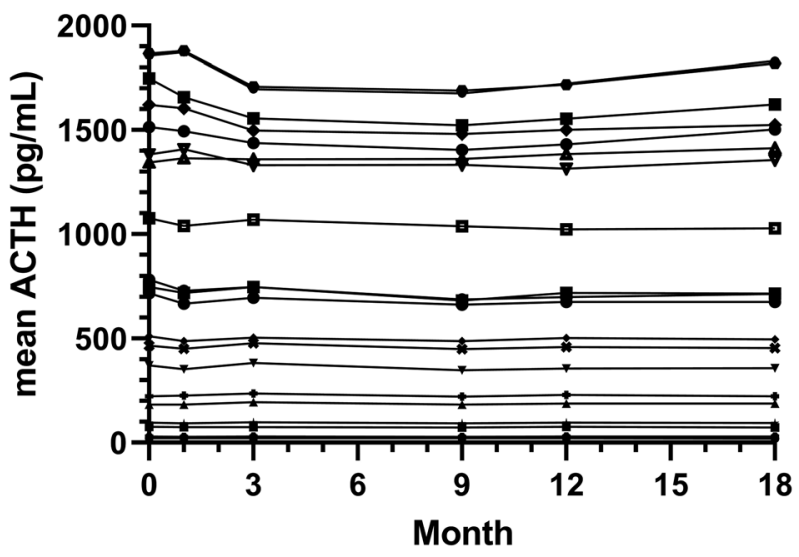

Neat Specimens Stored at $-70^{\circ} \mathrm{C}$

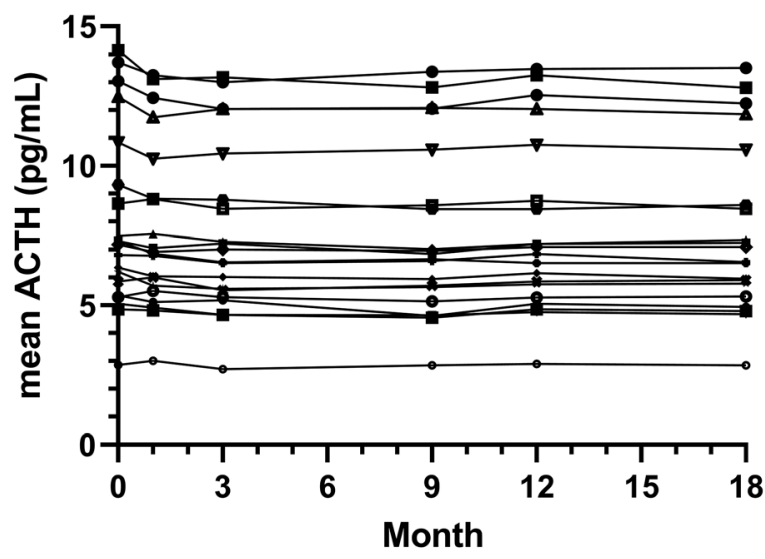

Spiked Specimens Stored at $-70^{\circ} \mathrm{C}$

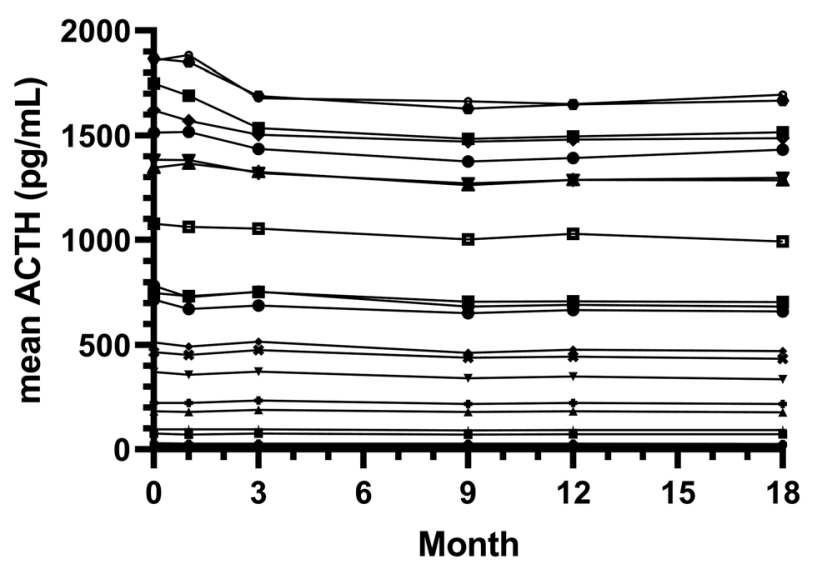

Figure 1: ACTH levels in individual neat and spiked human EDTA plasma specimens during 18 months of storage.

Each line represents the mean (of five replicates) ACTH $\left(\mathrm{pg} / \mathrm{mL}\right.$ ) results of a single donor. Specimens were stored at $-20^{\circ} \mathrm{C}$ (left panel) and $-70^{\circ} \mathrm{C}$ (right panel), neat (upper panel) or spiked (lower panel) at different levels. ACTH was measured using the Abott ACTH immunoassay.

influence on the ACTH levels in these specimens measured by the ARCHITECT ACTH assay. In both neat and spiked specimens at the two storage conditions, ACTH levels remained relatively stable over time with only minimal changes in ACTH levels, as depicted in Figures 1 and 2. After storing neat specimens at $-20^{\circ} \mathrm{C}$ or $-70^{\circ} \mathrm{C}$ for one and a half years, ACTH levels showed a minimal relative shift of $5.5 \%$ at $-20{ }^{\circ} \mathrm{C}$ and $-4.4 \%$ at $-70{ }^{\circ} \mathrm{C}$ storage, which are within the assay imprecision. Spiked specimens stored at $-70^{\circ} \mathrm{C}$ showed more instability of ACTH at one and a half years which was highest for specimens spiked at the middle (500-1,000 pg/mL) and higher level (1,500-1,800 pg/ $\mathrm{mL})$. Although absolute changes in ACTH levels were substantial at this high concentration level, relative \% shifts at one and a half years were limited to $10.6 \%$, as depicted in Table 1. Experiment 2: Storing specimens for up to 4 or 6 years did significantly reduce detectable ACTH levels in native patient plasma specimens as depicted in Table 2 and Figure 3. After 4 years of storage at $-20{ }^{\circ} \mathrm{C}$, ACTH levels were $74.8 \%$, whereas after 6 years of storage ACTH levels were only $46.2 \%$ of the original ACTH levels measured using the Liaison immunoassay.

\section{Discussion}

Long-term specimen stability information is important for a variety of purposes that may be related to clinical management and clinical trials that generally utilize aged specimens. The long-term frozen storage stability of ACTH is unknown. This may result in incorrect medical decision making or false scientific conclusions based 


\section{Neat specimens}

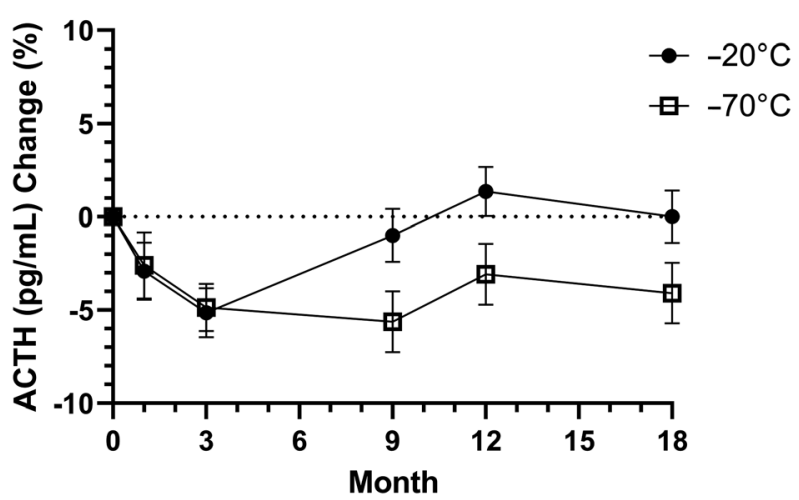

Spiked specimens

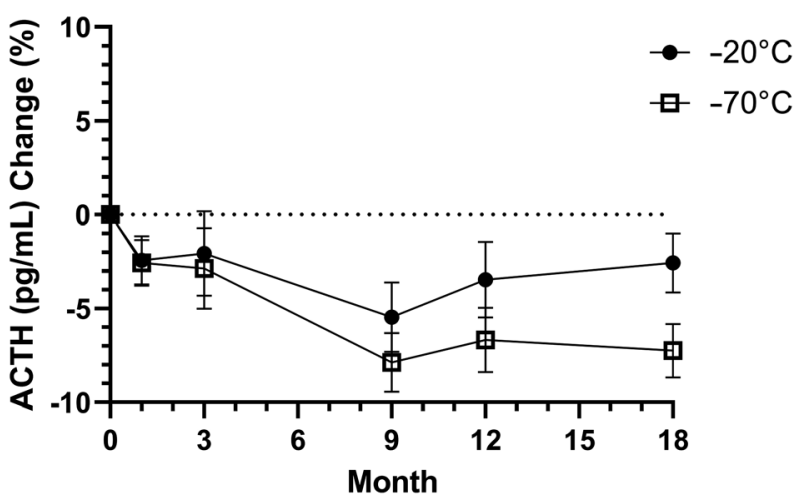

Figure 2: Relative ACTH levels in neat and spiked human EDTA plasma specimens during 18 months of storage. ACTH was measured using the Abbott ACTH immunoassay. Error bars indicate the $95 \%$ confidence interval.

Table 1: SICS regression, shift and \%shift summary of ACTH in neat and spiked specimens from healthy controls.

\begin{tabular}{|c|c|c|c|c|c|c|}
\hline Specimen & $\begin{array}{r}\text { Storage } \\
\text { condition }\end{array}$ & $\begin{array}{r}\text { Common } \\
\text { slope }\end{array}$ & $\begin{array}{r}\text { Slope } \\
\text { p-value }\end{array}$ & $\begin{array}{r}\text { Shift }^{\mathrm{a}} \text { at } \\
18 \mathrm{months} \\
\mathrm{pg} / \mathrm{mL}\end{array}$ & $\begin{array}{r}\text { Specimen } \\
\text { level, } \\
\mathrm{pg} / \mathrm{mL}\end{array}$ & $\begin{array}{l}\% \text { Shift }^{\mathrm{b}} \text { at } \\
18 \text { months }\end{array}$ \\
\hline \multirow[t]{4}{*}{ Neat } & $-20^{\circ} \mathrm{C}$ & 0.0005 & 0.0000 & 0.3 & 5.0 & 5.5 \\
\hline & & & & & 15.0 & 1.8 \\
\hline & $-70^{\circ} \mathrm{C}$ & -0.0004 & 0.0011 & -0.2 & 5.0 & -4.4 \\
\hline & & & & & 15.0 & -1.5 \\
\hline \multirow[t]{4}{*}{ Spiked low $(21.0-223 \mathrm{pg} / \mathrm{mL})$} & $-20^{\circ} \mathrm{C}$ & -0.0005 & 0.8540 & -0.3 & 70.0 & -0.4 \\
\hline & & & & & 100 & -0.3 \\
\hline & $-70^{\circ} \mathrm{C}$ & -0.0068 & 0.0092 & -3.7 & 70.0 & -5.3 \\
\hline & & & & & 100 & -3.7 \\
\hline \multirow[t]{4}{*}{ Spiked medium (371-1,077 pg/mL) } & $-20^{\circ} \mathrm{C}$ & -0.0504 & 0.0014 & -27.5 & 500 & -5.5 \\
\hline & & & & & 1,000 & -2.7 \\
\hline & $-70^{\circ} \mathrm{C}$ & -0.0969 & 0.0000 & -52.8 & 500 & -10.6 \\
\hline & & & & & 1,000 & -5.3 \\
\hline \multirow[t]{4}{*}{ Spiked high $(1,345-1,866$ pg/mL) } & $-20^{\circ} \mathrm{C}$ & -0.0840 & 0.1023 & -45.8 & 1,500 & -3.1 \\
\hline & & & & & 1,800 & -2.5 \\
\hline & $-70^{\circ} \mathrm{C}$ & -0.2621 & 0.0000 & -142 & 1,500 & -9.5 \\
\hline & & & & & 1,800 & -7.9 \\
\hline
\end{tabular}

${ }^{a}$ Shift=slope $\times 545$ days. ${ }^{\text {b } \% S h i f t=s h i f t ~} /$ specimen level $\times 100$. ACTH was measured using the Abbott ACTH immunoassay.

upon ACTH measurements in specimens stored for several months or even years. Here we show that ACTH levels in EDTA plasma aliquots from healthy controls are remarkably stable when stored at $-20^{\circ} \mathrm{C}$ or $-70^{\circ} \mathrm{C}$ for up to one and a half years. We observed only small changes of ACTH levels in neat specimens over time; these changes in ACTH levels were within confirmed assay imprecision and are therefore not critically different nor considered clinically relevant. In spiked specimens, changes in ACTH levels were larger, but did not increase beyond 11\% (Experiment 1). ACTH levels in patient specimens, however, showed significant reductions following continued storage at $-20{ }^{\circ} \mathrm{C}$ (Experiment 2).
These experiments suggest that ACTH degradation is a continuing process and increases over time.

There are however several limitations. The data described above originate from two experiments, differing in design, study population, and the specific immunoassay used. Therefore, findings from both experiments cannot be directly compared. Findings from Experiment 1 indicate that ACTH levels are remarkably stable in human plasma specimens up to one and a half years. Although in general long-term storage at $-70{ }^{\circ} \mathrm{C}$ is preferable to $-20{ }^{\circ} \mathrm{C}$ [9], we now showed that storing ACTH specimens in a $-70{ }^{\circ} \mathrm{C}$ freezer for up to one and a half years is not beneficial over storing specimens in a more frequently available $-20{ }^{\circ} \mathrm{C}$ 
Table 2: ACTH levels in native patient specimens at baseline (TO) and following 4 or 6 years of storage at $-20^{\circ} \mathrm{C}$.

\begin{tabular}{|c|c|c|c|c|}
\hline & TO $(n=20)$ & $T 4(n=20)$ & TO $(n=39)$ & T6 $(n=39)$ \\
\hline Absolute ACTH median ( $25-75 \%$ percentile) & $\begin{array}{r}28.7 \mathrm{pg} / \mathrm{mL} \\
(9.3-76.0)\end{array}$ & $\begin{array}{r}17.7 \mathrm{pg} / \mathrm{mL}^{\mathrm{a}} \\
(7.7-69.9)\end{array}$ & $\begin{array}{l}200 \mathrm{pg} / \mathrm{mL} \\
(41.4-332)\end{array}$ & $\begin{array}{r}82.6 \mathrm{pg} / \mathrm{mL}^{\mathrm{a}} \\
(16.6-188)\end{array}$ \\
\hline Relative ACTH median (25-75\% percentile) & $100 \%$ & $\begin{array}{r}74.8 \% \\
(61.5-83.6)\end{array}$ & $100 \%$ & $\begin{array}{r}46.2 \% \\
(41.5-46.0)\end{array}$ \\
\hline
\end{tabular}

${ }^{a}$ Wilcoxon rank test, $p<0.001$ vs. TO. ACTH was measured using the Diasorin ACTH assay.
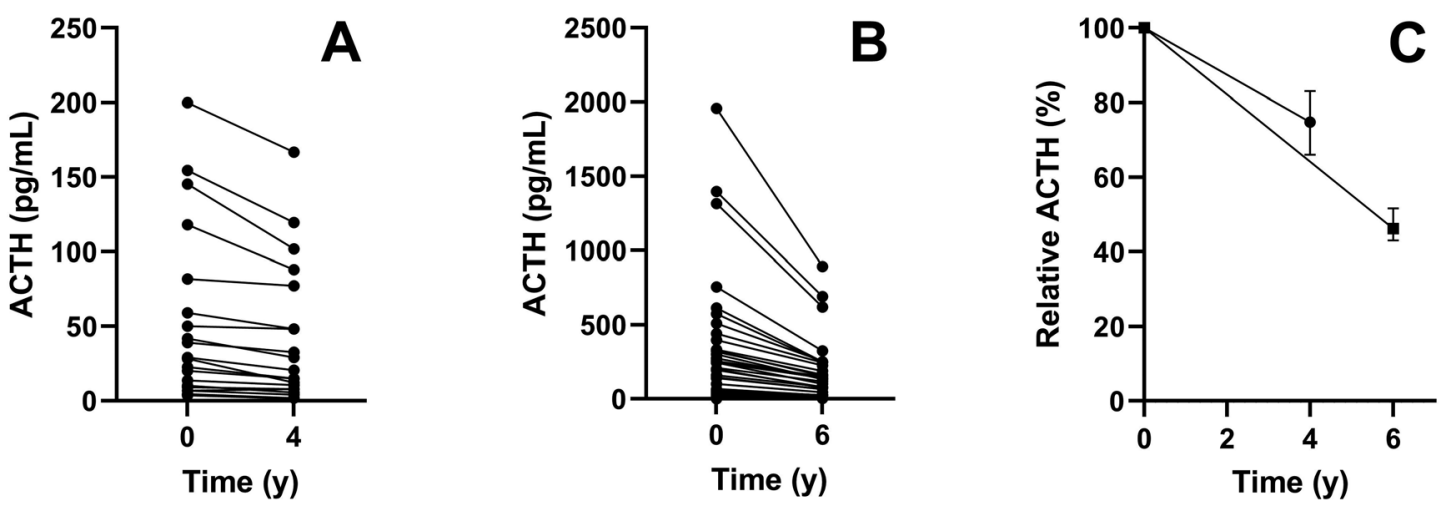

Figure 3: ACTH levels in human EDTA plasma specimens at baseline and following long-term storage.

Samples were stored for 4 (A) or 6 (B) years at $-20^{\circ} \mathrm{C}$. Relative change in ACTH levels with error bars indicating the $95 \%$ confidence interval are depicted in (C). ACTH was measured using the Diasorin ACTH assay.

freezer. This is important information for researchers, medical doctors and laboratory specialists dealing with concerns about storage of plasma specimens for ACTH measurements future (batch) analysis [8].

Theoretically, instability of ACTH may have been masked by potential instability of the calibrator used in Experiment 1. If the calibrator degraded over time, instability of the specimens could have been missed. Although the same calibrator was used during the 18 months study, degradation of the calibrator is highly unlikely because the calibrator is a stable formulation in a synthetic matrix (not comparable to a plasma matrix with proteases), and accelerated stress stability studies at a series of temperatures above freezing with use of an Arrhenius equation to model calibrator stability supported that calibrators were stable (data not shown). The findings from Experiment 2 show that prolonged storage at $-20^{\circ} \mathrm{C}$ of native specimens from patients resulted in a significant reduction of ACTH levels, with specimens stored for 6 years being more affected than specimens stored for 4 years. Specimens were collected from patients visiting Amsterdam UMC for whom ACTH levels were requested as part of routine diagnostics of primary adrenal insufficiency, pituitary insufficiency or Cushing syndrome, including sinus petrosal samplings (explaining the high ACTH levels in the 6 years storage group). The reduction of ACTH levels was not related to the reason for referral (data not shown).

In theory, the changes in ACTH levels over time could have been caused by changes in the standardization of the Liaison ACTH assay over time. This is however unlikely as trend analyses based upon internal and external quality control data in the Amsterdam UMC laboratory show no indications for standardization changes (explaining the $>25 \%$ reduction in ACTH levels) over time. Unfortunately, specimens were only stored at $-20^{\circ} \mathrm{C}$ and not also at $-70^{\circ} \mathrm{C}$; therefore, we cannot deliberate on the effect of prolonged storage time (4-6 years) at different storage temperatures.

As mentioned above, studies were performed using two different ACTH immunoassays; a newly developed ARCHITECT $^{\circledR}$ i2000 $_{\text {SR }}$ (Abbott) automated immunoassay (Experiment 1) and a routine ACTH CLIA (Diasorin) test (Experiment 2). These ACTH assays, like other endocrine immunoassays, suffer from standardization differences due to absence of a commutable reference material and internationally accepted reference method $[1,13,14]$. Both assays are standardized using internally produced working references or standards. Therefore, findings obtained with the Abbott and Diasorin assay in this study may not be compared. Furthermore, the use of different immunoassays may cause differences in detection of possible ACTH 
fragments, which may increase (e.g. by oxidation) during long-term storage. For the Abbott assay, no cross-reactivity was observed for $\mathrm{ACTH}_{(1-10)}, \mathrm{ACTH}_{(11-24)}, \mathrm{ACTH}_{(1-24)}$, $\mathrm{ACTH}_{(1-17)}$ and $\mathrm{ACTH}_{(18-39)}$ (all tested after spiking 500, 5,000 and 50,000 pg/mL) [11]. The Diasorin ACTH assay showed no evidence for cross-reactivity of $\mathrm{ACTH}_{(1-24)}$ $(1,400 \mathrm{pg} / \mathrm{mL}), \mathrm{ACTH}_{(11-24)}(1,600 \mathrm{pg} / \mathrm{mL})$ and $\mathrm{ACTH}_{(18-39)}$ $(9,800 \mathrm{pg} / \mathrm{mL})$ [12]. Finally, the plasma specimens from Experiment 2 were stored in polystyrene tubes. Polystyrene is a thermoplastic polymer which is more porous than polypropylene (used in Experiment 1). In addition, tube sizes were different; $2 \mathrm{~mL}$ (Experiment 1) vs. $5 \mathrm{~mL}$ (Experiment 2). The bigger head-space in the $5 \mathrm{~mL}$ tubes as well as the more porous tube material and cap type may have caused additional degradation of ACTH in Experiment 2.

This article describes two experiments performed in different settings; the first during manufacturer evaluation and the second during routine workload conditions. Despite the limitations mentioned above, we conclude that ACTH concentrations are influenced by storage time. We showed that up to one and a half years ACTH levels measured using the Abbott research only assay are stable when stored at $-20^{\circ} \mathrm{C}$ but that with longer storage times at $-20^{\circ} \mathrm{C}$ significant reductions in ACTH levels can be expected. We recommend consideration of storage time and storage temperature and standardization differences when planning long-term storage of plasma specimens for future ACTH measurements.

Acknowledgments: We thank Paula van Oosten for writing assistance.

Research funding: This research was in part supported by Abbott Laboratories. Abbott Laboratories was involved in study design, data collection, analysis and interpretation, and writing of the report (see authorlist).

Author contributions: All authors have accepted responsibility for the entire content of this manuscript and approved its submission.

Competing interests: Authors state no conflict of interest. Informed consent: Informed consent was obtained from all individuals included in this study.

Ethical approval: The local Institutional Review Board deemed the study exempt from review.

\section{References}

1. Talbot JA, Kane JW, White A. Analytical and clinical aspects of adrenocorticotrophin determination. Ann Clin Biochem 2003;40: 453-71.

2. Ellis JM, Livesey JH, Evans MJ. Hormone stability in human whole blood. Clin Biochem 2003;36:109-12.

3. Livesey JH, Dolamore B. Stability of plasma adrenocorticotrophic hormone (ACTH): influence of hemolysis, rapid chilling, time, and the addition of a maleimide. Clin Biochem 2010;43:1478-80.

4. Toprak B, Yalcin H, Arı E, Colak A. EDTA interference in electrochemiluminescence ACTH assay. Ann Clin Biochem 2016; 53:699-701.

5. Reisch N, Reincke M, Bidlingmaier M. Preanalytical stability of adrenocorticotropic hormone depends on time to centrifugation rather than temperature. Clin Chem 2007;53:358-9.

6. Chakera AJ, McDonald TJ, Knight BA, Vaidya B, Jones AG. Current laboratory requirements for adrenocorticotropic hormone and renin/aldosterone sample handling are unnecessarily restrictive. Clin Med (Lond) 2017;17:18-21.

7. Hillebrand JJ, Heijboer AC, Endert E. Effects of repeated freezethaw cycles on endocrine parameters in plasma and serum. Ann Clin Biochem 2017;54:289-92.

8. Hillebrand JJ, Wickenhagen WV, Heijboer AC. Improving science by overcoming laboratory pitfalls with hormone measurements. J Clin Endocrinol Metab 2021;25: e1504-12.

9. Gislefoss RE, Grimsrud TK, Mørkrid L. Stability of selected serum proteins after long-term storage in the Janus Serum Bank. Clin Chem Lab Med 2009;47:596-603.

10. Quinn FA. Chapter 34; Architect ${ }^{\circledR} i 2000$ and $i 2000^{\circledR}$ SR analyzers. In: Wild D, editor. The immunoassay handbook. Oxford: Elsevier Ltd; 2005:406-11 pp.

11. Datwyler M, Marcinkus MA, Cheng K, Pandya K, Peart JE, Dawn M, et al. Analytical performance assessment of an automated research use only immunoassay for Abbott's alinity I and ARCHITECT I systems. In: 72nd AACC annual scientific meeting abstract; 2020.

12. Banci M, Schlett R, Markowitz G, Brommel-Hildebrand G, Lacmann R. Development of a specific and fully automated adrenocorticotropic hormone (ACTH) assay on the LIAISON ${ }^{\circledR}$ immunoassay analyzer. In: 58th AACC annual scientific meeting abstract; 2006.

13. Dobson SH, Gibson S, White A. Assessment of the potency of different standards in the immunoradiometric assay of ACTH. Ann Clin Biochem 1989;26:96-101.

14. Pecori Giraldi F, Saccani A, Cavagnini F. Study group on the hypothalamo-pituitary-adrenal axis of the Italian Society of Endocrinology. Assessment of ACTH assay variability: a multicenter study. Eur J Endocrinol 2011;164:505-12. 